\title{
BMJ Open A longitudinal study to identify the influence of quality of chronic care delivery on productive interactions between patients and (teams of) healthcare professionals within disease management programmes
}

\author{
Jane Murray Cramm, Anna Petra Nieboer
}

To cite: Cramm JM, Nieboer AP. A longitudinal study to identify the influence of quality of chronic care delivery on productive interactions between patients and (teams of) healthcare professionals within disease management programmes. BMJ Open 2014;4:e005914. doi:10.1136/bmjopen-2014005914

- Prepublication history and additional material is available. To view please visit the journal (http://dx.doi.org/ 10.1136/bmjopen-2014005914).

Received 13 June 2014 Revised 29 August 2014 Accepted 1 September 2014

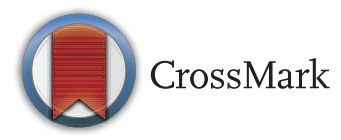

Department of Health Policy \& Management (iBMG), Erasmus University Rotterdam, Rotterdam, The Netherlands

Correspondence to Dr Jane Murray Cramm; cramm@bmg.eur.nl

\section{ABSTRACT}

Objective: The chronic care model is an increasingly used approach to improve the quality of care through system changes in care delivery. While theoretically these system changes are expected to increase productive patient-professional interaction empirical evidence is lacking. This study aims to identify the influence of quality of care on productive patient-professional interaction.

Setting: Longitudinal study in 18 Dutch regions. Participants: Questionnaires were sent to all 5076 patients participating in 18 Disease Management Programmes (DMPs) in 2010 (2676 (53\%) respondents). One year later (T1), 4693 patients still participating in the DMPs received a questionnaire (2191 (47\%) respondents) and 2 years later (in 2012; T2) 1722 patients responded (out of $4350 ; 40 \%$ response).

Interventions: DMPs

Primary outcome measure: Patients' perceptions of the productivity of interactions (measured as relational coordination/coproduction of care) with professionals. Patients were asked about communication dimensions (frequent, accurate, and problem-solving communication) and relationship dimensions (shared goals and mutual respect).

Findings: After controlling for background characteristics these results clearly show that quality of chronic care (T0), first-year changes in quality of chronic care (T1-T0) and second-year changes in quality of chronic care (T2-T1) predicted productive interactions between patients and professionals at T2 (all at $p \leq 0.001$ ). Furthermore, we found a negative relationship between lower educational level and productive interactions between patients and professionals 2 years later.

Conclusions: We can conclude that successfully dealing with the consequences of chronic illnesses requires proactive patients who are able to make productive decisions together with their healthcare providers. Since patients and professionals share responsibility for management of the chronic illness, they must also share control of interactions and decisions. The importance of patient-centeredness is

\section{Strengths and limitations of this study}

Strength of this study is that we investigated 18 disease management programmes targeting patients with cardiovascular diseases $(n=9)$, chronic obstructive pulmonary disease $(n=4)$, heart failure $(n=1)$, comorbidity $(n=1)$, and diabetes $(n=3)$.

- This study investigated long-term (two-year changes) effects of quality of care on productive interactions between patients and (teams of) healthcare professionals.

- The importance of patient-centeredness is growing and this study reports a first example of how quality of chronic care stimulates productive interactions between patients and healthcare professionals.

- Limitation of this study is that we did not have a control group for each disease management programme.

growing and this study reports a first example of how quality of chronic care stimulates productive interactions between patients and professionals.

\section{INTRODUCTION}

Chronic diseases, such as cardiovascular diseases, chronic obstructive pulmonary disease, and diabetes, are major causes of death and disability worldwide, and their prevalence continues to increase. ${ }^{1}$ Current care, however, is often driven by the treatment of acute conditions, despite evidence that chronically ill patients benefit from a structured and proactive approach tailored to their individual needs. ${ }^{2}$

The chronic care model (CCM) is an increasingly used approach to improving the quality of chronic care. ${ }^{3-7}$ In the 
Netherlands, many disease management programmes (DMPs), which employ coordinated disease management interventions to improve quality of chronic care, are based on this model. ${ }^{8-10}$ The CCM provides a framework guiding the shift from acute and reactive care delivery to the provision of chronic and proactive care that is organised, structured, and planned. This transition can be achieved through the development of effective multidisciplinary teams in combination with planned interactions with chronically ill patients. ${ }^{5}$ The model of high-quality chronic care delivery seeks to promote a fuller understanding of each patient's life and preferences, tailoring care to his or her needs and empowering him or her as a proactive participant in care delivery. ${ }^{11} 12$ These concepts are often associated with the term 'patient-centered care. ${ }^{13}$

The essential element of good chronic illness care is productive interaction between patients and (teams of) healthcare professionals, as opposed to interactions that tend to be frustrating when coordination among professionals and with patients is not prioritised. DMPs based on the CCM are expected to achieve such interaction, thereby improving patient centeredness and health outcomes. Productive interaction means that the work of evidence-based chronic disease care gets done systematically and meets patients' needs. ${ }^{14}$ While modern medical care is sometimes influenced by the two separate paradigms of 'evidence-based medicine' (ie, decision-making about care based on research-supported risk estimates and clinical expertise) and 'patient-centered medicine, ${ }^{15}$ the CCM provides a framework of care delivery that brings these separate worlds together. ${ }^{13}$ Productive interaction requires that patients are informed (ie, have sufficient information based on evidence-based medicine to make wise decisions related to their illness) and activated (ie, understand the importance of their role in managing the illness). These objectives may be difficult to achieve for chronically ill patients with low educational levels or different ethnic/cultural backgrounds. Earlier research showed that better educated patients receive higher quality of chronic care delivery compared to lower educated patients, which may be caused by differences in the behaviour of professionals toward different patient groups as well as different demands or ability to clearly explain things among these patients. ${ }^{16}$ Hence the quality of patient-professional interaction may vary between higher and lower education patients. Besides informed and activated patients, high-quality care requires teams of care providers that are organised, trained, and equipped to conduct productive interaction. Productive interactions between professionals may be recognised by accurate, frequent, and problem-solving communication that is supported by relationships based on shared goals and mutual respect, which enables healthcare organisations to better achieve their desired outcomes. Jody Hoffer Gittell ${ }^{17} 18$ has demonstrated that this concept, known as 'relational coordination,' is an important predictor of a team's ability to achieve its performance objectives.
Relational coordination is concerned with the quality of interactions and productive collaboration. An instrument for the measurement of this concept was originally developed for the airline industry, ${ }^{19}$ but has been applied in hospital, ${ }^{2021}$ primary care, ${ }^{9}{ }^{10}$ and community care ${ }^{22}$ settings to assess relational coordination among healthcare professionals. However, relational coordination has not been investigated previously in the context of the coproduction of care, which refers to the existence of high-quality interactions and productive collaboration between patients and healthcare professionals. Although it has been investigated between healthcare professionals and family caregivers. ${ }^{23} 24$

The CCM framework outlines the following system changes that are expected to result in productive interaction between patients and healthcare providers: selfmanagement support (providing patient-centered care, empowering patients to self-manage their chronic conditions, and making them proactive participants in care delivery), delivery system design (which guides healthcare professionals' manner of interacting with and delivering care to chronically ill patients), decision support (enabling identification of the best (evidence-based) care and promoting informed decision-making in each patient consultation), and clinical information systems (appropriate use of information systems for care to support productive interaction between proactive patients and healthcare professionals). ${ }^{13}$ Although DMPs based on the CCM have been shown to improve the quality of chronic care delivery ${ }^{25}$ process outcome measures (eg, numbers of prescribed medications and tests), ${ }^{7}$ clinical outcomes (eg, number of patients with haemoglobin A1c levels $>7 \%$ ), ${ }^{26}$ health behaviours (eg, smoking cessation, increased physical activity), ${ }^{27}$ and interaction among healthcare professionals over time, ${ }^{10}$ as well as preventing disease complications, ${ }^{28}$ evidence that such programmes lead to productive interactions between patients and healthcare providers is lacking. Thus, the aim of this study was to examine whether the quality of chronic care delivery in the context of DMPs predicts the productivity of patient-professional interactions, and thus the patient-centeredness of care.

\section{METHODS}

To describe the content and experiences of DMPs, we used a mixed-methods approach. In such an approach, both qualitative and quantitative data are gathered simultaneously and are mixed during the analysis phase to broaden the scope of understanding.

\section{Quantitative analysis}

\section{Participants}

For the quantitative longitudinal study, patients participating in 18 Dutch DMPs were asked to assess the quality of chronic care delivery over a 2-year period (2010-2012) and the productivity of interactions with healthcare professionals. The study was approved by the 
ethics committee of the Erasmus University Medical Center of Rotterdam and informed consent was obtained from all participants. Participating DMPs were characterised as collaborations between care sectors (eg, between general practitioners and hospitals) or within primary care settings (eg, among physiotherapists, dieticians and general practitioners). They targeted patients with cardiovascular diseases $(n=9)$, chronic obstructive pulmonary disease $(n=4)$, heart failure $(n=1)$, comorbidity $(n=1)$, and diabetes $(n=3) .{ }^{29}$ All of these DMPs included self-management interventions, such as patient education, lifestyle coaching, and motivational interviewing. They implemented care standards and protocols built on multidisciplinary guidelines and supported by information and communications technology (ICT) tools, such as integrated information systems. In addition, all DMPs provided training for healthcare professionals and reallocated tasks from general practitioners or specialists to practice assistants or nurses. They used more effective information transfer and appointment scheduling practices, as well as planned interactions among healthcare professionals and regular follow-up meetings of care teams. ${ }^{29}{ }^{30}$ In online supplementary appendix 1 a full overview of implemented CCM interventions within each DMP can be found.

In 2010, we sent questionnaires to all 5076 patients participating in the 18 DMPs, and received responses from $2676(53 \%)$ patients. One year later (in 2011), questionnaires were distributed to 4693 patients still participating in the DMPs and completed by $2191(47 \%)$ respondents. In 2012, $1722(40 \%)$ of 4350 DMP participants completed the questionnaires. A total of 981 patients completed questionnaires at all three time points.

\section{Measures}

The questionnaires were used to collect information about participants' background characteristics, such as age, gender, marital status, and education (dichotomised as low (no school or primary education) or high (more than primary education)). We asked respondents about their experiences with care delivery. This concerns the care they receive from their team of healthcare professionals (eg, specialist, GP, practice assistant, dietician) who treat their chronic condition. We assessed productive interactions among patients and (teams of) healthcare professionals using an adjusted version of the Relational Coordination instrument. Although originally developed to assess quality of communication and coordination among professionals this instrument has also been used to assess relational coordination between healthcare professionals and informal caregivers of patients. ${ }^{23}$ We used a modified version of the relational coordination instrument (five items rated on a four-point scale; excellent reliability (Cronbach's $\alpha=0.96)$ ) to elicit patients' perceptions of the productivity of interactions (characterised as relational coordination/coproduction of $(\mathrm{care})^{31}$ with general practitioners, practice nurses, dieticians, physical therapists, medical specialists, and nurses. Patients were asked about three communication dimensions (frequent, accurate, and problem-solving communication) and two relationship dimensions (shared goals and mutual respect). We did not include the relational coproduction/coordination aspects timely communication and shared knowledge.

We used a short (11-item) version of the Patient Assessment of Chronic Illness Care (PACIC), ${ }^{32}$ called the PACIC-S, ${ }^{33}$ to assess patients' perspectives on the alignment of primary care with the CCM. The PACIC has been used nationally and internationally to evaluate the delivery of CCM components to patients with diverse chronic health conditions (diabetes, osteoarthritis, depression, asthma, hypertension, chronic obstructive pulmonary disease, and cardiovascular conditions). ${ }^{32-37}$ The PACIC-S, which we previously developed and validated, asks patients to report the extent to which they have received specific actions and care congruent with various aspects of the CCM during the past 6 months. Responses were structured by a five-point scale (ranging from 'almost never' to 'nearly always') in 2010 and 2011 and a four-point scale (ranging from 'never' to 'always') in 2012; scores were standardised for comparability. Cronbach's $\alpha$ values of the PACIC-S at the three time points $(2010,0.89 ; 2011,0.86 ; 2012,0.88)$ indicated good reliability.

\section{Statistical analyses}

First, descriptive statistics were used to describe the study population of patients who completed questionnaires at all three time points (2010, 2011 and 2012). Second, we employed correlation analyses to investigate associations among individual characteristics of patients, the quality of chronic care (as assessed by number of implemented disease management interventions as well as perceived (changes in) chronic care quality), and productive interaction between patients and (teams of) healthcare professionals as perceived by patients. Third, we used a multilevel random-effects model to investigate the predictive role of (changes in) the quality of chronic care delivery in productive patient-professional interaction while controlling for patients' age, gender, educational level, and marital status at baseline. All independent variables were standardised. Results were considered statistically significant if two-sided $p$ values were $\leq 0.05$.

\section{Qualitative analysis}

For the qualitative part of the study structured interviews were held with all project leaders from the DMPs. A template based on the CCM was developed for the collection of qualitative data on various approaches to improve care for chronically ill patients within these Dutch DMPs. This template incorporates the following six interrelated components of healthcare systems: (1) self-management support, (2) delivery system design, (3) decision support, (4) clinical information systems, (5) healthcare organisation, and (6) community linkages. 
Project leaders were interviewed and asked about the implementation of their interventions and their experiences with improving patient outcomes using this CCM template. All interviews were approximately 60-90 min in length and recorded with permission. After finalising the templates they were sent back to the project leaders for a final check. In online supplementary appendix $1 \mathrm{a}$ full overview is given of all CCM interventions implemented within each DMP. Earlier research showed that a constellation of interventions is needed and that a DMP is deemed to be based on the CCM if their constellation of interventions attempted to make changes can be mapped to at least four elements of the CCM. ${ }^{6}{ }^{7}$ The total number of interventions implemented within each DMP ranged from 13 to 43. All DMPs implemented interventions within at least four of the CCM dimensions and can therefore be considered to be a DMP based on the CCM. ${ }^{6}$ We scored DMPs using 34 (which is $60 \%$ out of a total of 56 potential interventions) disease management interventions and implementing interventions within all six CCM dimensions or more as high-quality of care (1) versus DMPs with fewer disease management interventions (0). Based on this criteria, $33 \%$ of the DMPs are considered to be 'high-quality' DMPs.

\section{RESULTS}

Table 1 displays the characteristics of the 981 patients who completed questionnaires at all three time points (2010, 2011 and 2012). Of these respondents, $45 \%$ were female, $37 \%$ had low educational levels, and $28 \%$ were

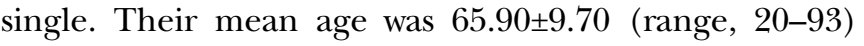
years.

Table 1 Descriptive statistics for 981 chronically III patients participating in 18 dutch disease management programs

\begin{tabular}{|c|c|c|}
\hline & $\begin{array}{l}\text { Mean } \pm S D \\
\text { (range) or } \\
\text { percentage }\end{array}$ & $\begin{array}{l}\text { Number of } \\
\text { respondents }\end{array}$ \\
\hline \multicolumn{3}{|c|}{ Baseline (2010) characteristics } \\
\hline Age (years) & $65.90 \pm 9.70(20-93)$ & 934 \\
\hline Gender (female) & 45 & 954 \\
\hline $\begin{array}{l}\text { Marital status } \\
\text { (single) }\end{array}$ & 28 & 971 \\
\hline $\begin{array}{l}\text { Educational level } \\
\text { (low) }\end{array}$ & 37 & 930 \\
\hline \multicolumn{3}{|c|}{ Perceived quality of chronic care } \\
\hline 2010 & $2.96 \pm 0.88(1-5)$ & 907 \\
\hline 2011 & $2.93 \pm 0.84(1-5)$ & 918 \\
\hline 2012 & $2.13 \pm 0.71(1-4)$ & 880 \\
\hline $\begin{array}{l}\text { Perceived productive } \\
\text { interaction with (teams } \\
\text { of) healthcare } \\
\text { professionals (2012) }\end{array}$ & $2.94 \pm 0.73(1-4)$ & 971 \\
\hline
\end{tabular}

Associations among individual characteristics, highquality of chronic care according to number of implemented interventions in each DMP, the quality of chronic care as perceived by patients, and productive interaction between patients and care providers are displayed in table 2. These results show that high-quality of chronic care $(p \leq 0.01)$ as well as patients' perceptions of the quality of chronic care delivery at all three time points were related significantly to their characterisation of productive interactions in 2012 (all $\mathrm{p} \leq 0.001$ ). In addition, patients' perceptions of productive interaction in 2012 were associated negatively with low educational level, meaning that less educated patients found interaction to be less productive than did more educated patients.

Table 3 displays the results of the multilevel analyses, which controlled for age, marital status, educational level, and gender at baseline. These results clearly show that both high-quality of care as assessed by number of implemented disease management interventions $(p \leq 0.05)$, patients' perceptions of the quality of chronic care in $2010(\mathrm{p} \leq 0.001)$, as well as changes in the perceived quality of this care in the first (2011-2010) $(p \leq 0.001)$ and second (2012-2011) years $(p \leq 0.001)$, predicted the existence of productive interaction between patients and healthcare professionals in 2012 . As in the correlation analyses, low education level was related negatively to productive interaction in 2012 in the multilevel analyses.

\section{DISCUSSION}

To our knowledge, this is the first study to investigate the ability of DMPs based on the CCM to improve the productivity of interactions between chronically ill patients and (teams of) healthcare professionals. The results clearly show that (changes in) the quality of chronic care delivery predicted the existence of productive interactions over time. Thus, the quality of communication and collaboration between informed, activated patients and organised, trained and equipped healthcare teams depends on the quality of care delivery. Interaction must assure consistent patient-centered support, with an emphasis on empowering patients to be proactive and participate in care delivery. ${ }^{13}$ Active participation in goal setting and the development of action plans not only represents high-quality chronic care delivery, stimulating productive interaction, but also appears to be consonant with emerging concepts of patient-centered care. ${ }^{13} 38$

We found that less educated patients perceived less productive interaction than did more educated patients during the 2-year period of DMP participation. Education level may have affected the way in which patients coped with a chronic condition over time. For example, more educated people are expected to be better at self-management, getting necessary care, and demanding better care ${ }^{16}$ making them more proactive participants in care delivery. On the other hand, healthcare professionals must be prepared to interact 
Table 2 Associations among individual characteristics, quality of chronic care, and productive interactions between patients and (teams of) healthcare professionals

$\begin{array}{llllllll}1 & 2 & 3 & 4 & 5 & 6 & 7 & 8\end{array}$

1. Age (2010)

2. Marital status (single; 2010)

3. Low educational level (2010)

4. Gender (female; 2010)

5. Quality of chronic care (2010)

6. Quality of chronic care (2011)

7. Quality of chronic care (2012)

8. High-quality of care $†$

9. Productive interactions between patients and (teams of) healthcare professionals (2012)

\section{$0.14^{* * *}$}

$0.11^{\star \star \star} \quad 0.09^{\star \star}$

$-0.11^{\star \star \star} \quad 0.21^{\star \star \star} \quad 0.14^{\star \star \star}$

$-0.09^{* *}-0.03-0.02$

$\begin{array}{lll}-0.12^{\star \star *} & -0.08^{*} & 0.02\end{array}$

$-0.11^{\star *}-0.03$

$-0.04 \quad 0.19$

$-0.05$

$-0.05$
0.00

$-0.11$

$-0.07^{\star}$
$-0.00$

$-0.03$

$-0.03$

$0.73^{\star}$

$-0.04$
$0.58^{* * *}$

$0.52^{\star * *} \quad 0.54^{\star * *}$

0.04

$0.32^{* * *}$
$-0.03$

$0.31^{\star \star *}$ $0.43^{\star * *} \quad 0.09^{\star *}$

${ }^{* * *} \mathrm{p} \leq 0.001,{ }^{* *} \mathrm{p} \leq 0.01,{ }^{*} \mathrm{p} \leq 0.05$ (two-tailed)

$\dagger$ Based on implemented interventions in the disease management programmes.

productively with all types of patients. The quality of care occurring during encounters between patients and healthcare professionals, however, has been found to differ due to bias (or prejudice) against minority patients (those with different cultural/ethnic backgrounds). ${ }^{39}$ This situation generates greater clinical uncertainty when interacting with minority patients and stems from care providers' beliefs (stereotypes) about these patients' behaviour or health. ${ }^{39}$ Such bias may also apply to patients with limited educational backgrounds. Less educated patients and healthcare professionals may find it more difficult to relate to and truly understand one other, resulting in inaccurate and infrequent 'fingerpointing' communication characterised by the lack of respect and knowledge sharing. Thus, care providers participating in DMPs must be aware of and trained to meet the challenge of supporting productive interaction between healthcare professionals and all patient

Table 3 Predictors of productive interactions between patients and (teams of) healthcare professionals in 2012, as assessed by multilevel regression analyses (random intercepts model)

\begin{tabular}{lcl}
\hline & B & SE \\
\hline Constant & $2.91^{\star \star \star}$ & 0.02 \\
Age (2010) & -0.01 & 0.03 \\
Marital status (single; 2010) & -0.01 & 0.02 \\
Low educational level (2010) & $-0.05^{\star}$ & 0.03 \\
Gender (female; 2010) & -0.02 & 0.03 \\
Quality of chronic care (2010) & $0.38^{\star \star \star}$ & 0.03 \\
First-year changes in quality of chronic & $0.30^{\star \star \star}$ & 0.04 \\
care (2011-2010) & & \\
$\begin{array}{l}\text { Second-year changes in quality of } \\
\text { chronic care (2012-2011) }\end{array}$ & $0.25^{\star \star \star}$ & 0.03 \\
High-quality of care $\dagger$ & & \\
\hline
\end{tabular}

${ }^{* * *} \mathrm{p} \leq 0.001,{ }^{* *} \mathrm{p} \leq 0.01,{ }^{*} \mathrm{p} \leq 0.05$ (two-tailed).

†Based on implemented interventions in the disease management programmes. Multilevel analyses included only respondents who filled in questionnaires at all three time points $(n=981 ; n=716$ after list wise deletion of missing cases). populations. Healthcare professionals should pay special attention to the stimulation of accurate, frequent, and problem-solving communication with less educated patients based on shared goals and mutual respect, which may entail the investment of additional time and resources by DMPs. Investing in healthcare professionals' competence to deal with diversity issues may help to improve the quality of care delivery and create productive interaction with patients.

Seeleman et $a l^{40}$ developed a framework to address cultural and ethnic diversity issues in medical education as a means of improving the quality of care by investing the professional competencies of knowledge, awareness, and ability. These competencies may also apply to the provision of care to less educated patients: knowledge of education-related health inequalities and the possible differential effects of treatment according to education level; awareness of how educational background affects (health) behaviour and coping with diseases, the social context in which less educated patients live and its effects on behaviour and health outcomes, and healthcare professionals' own prejudices and tendency to stereotype; and the ability to transfer information in an understandable way to less educated patients and adapt flexibly and creatively to new situations. Efforts to increase these competencies among healthcare professionals may stimulate productive interaction with less educated patients.

Some limitations should be considered when interpreting our study findings. Other aspects may also influence quality of chronic care delivery and the establishment of productive patient-professional interaction. Mackenzie et $a l^{41}$ for example identified a negative relationship between the severity of chronic diseases and quality of care delivery. Earlier we also found that quality of chronic care delivery was more difficult to achieve among patients with greater disease severity, namely patients with heart failure, comorbidity and severe COPD. ${ }^{30}$ Furthermore, we found that the quality of communication and coordination varies between professionals. ${ }^{9}$ Future research is 
necessary to identify patient as well as professional characteristics that effect patient-professional interactions. Finally, we did not include the relational coproduction/coordination aspects timely communication and shared knowledge. Future research is necessary investigating all seven aspects among patients.

We can conclude that patients' success in dealing with the consequences of chronic illness requires that they take a proactive role and are able to self-manage their condition and make productive decisions together with their healthcare providers. As patients and healthcare professionals share responsibility for the management of chronic illness, they must also share control over interactions and decisions. ${ }^{13}$ The importance of patientcenteredness is growing, and this study provides the first example of how productive patient-professional interactions depend on the quality of chronic care.

Acknowledgements This work was supported by The Netherlands Organization for Health Research and Development (ZonMw), a national organization that promotes quality and innovation in the field of health research and healthcare, initiating and fostering new developments (ZonMw project number 300030201 ). The authors are grateful to all patients and project leaders that participated in the research.

Contributors APN drafted the design for data gathering. JMC and APN were involved in acquisition of subjects and data, performed statistical analysis and interpretation of data. JMC drafted the manuscript and APN helped drafting the manuscript and contributed to refinement. Both authors have read and approved its final version.

Funding The Netherlands Organization for Health Research and Development (ZonMw).

Competing interests None.

Provenance and peer review Not commissioned; externally peer reviewed.

Data sharing statement No additional data are available.

Open Access This is an Open Access article distributed in accordance with the Creative Commons Attribution Non Commercial (CC BY-NC 4.0) license, which permits others to distribute, remix, adapt, build upon this work noncommercially, and license their derivative works on different terms, provided the original work is properly cited and the use is non-commercial. See: http:// creativecommons.org/licenses/by-nc/4.0/

\section{REFERENCES}

1. World Health Organization. The global strategy on diet, physical activity and health. Geneva: World Health Organization, 2008.

2. Lenfant C. Shattuck lecture-clinical research to clinical practicelost in translation? N Engl J Med 2003;349:868-74.

3. Wagner EH, Austin BT, Von Korff M. Organizing care for patients with chronic illness. Milbank Q 1996;74:511-44.

4. Wagner EH, Austin BT, Von Korff M. Improving outcomes in chronic illness. Manag Care Q 1996;4:12-25.

5. Wagner $\mathrm{EH}$, Austin BT, Davis $\mathrm{C}$, et al. Improving chronic illness care: translating evidence into action. Health Aff 2001;20:64-78.

6. Coleman K, Austin BT, Brach C, et al. Evidence on the chronic care model in the new millennium. Health Aff 2009;28:75-85.

7. Tsai AC, Morton SC, Mangione CM, et al. A meta-analysis of interventions to improve care for chronic illnesses. Am J Manag Care 2005;11:478-88.

8. Cramm JM, Strating MMH, Tsiachristas A, et al. Development and validation of a short version of the Assessment of Chronic Illness Care $(\mathrm{ACIC})$ in Dutch Disease Management Programs. Health Qual Life Outcomes 2011;9:49.

9. Cramm JM, Nieboer AP. Relational coordination promotes quality of chronic-care delivery in Dutch disease-management programs. Health Care Manage Rev 2012;37:301-9.
10. Cramm JM, Nieboer AP. In the Netherlands, rich interaction among professionals conducting disease management led to better chronic care. Health Aff 2012;31:2493-500.

11. Hibbard JH, Stockard J, Mahoney ER, et al. Development of the patient activation measure (PAM): conceptualizing and measuring activation in patients and consumers. Health Serv Res 2004;39:1005-26.

12. Anderson RM. Patient empowerment and the traditional medical model. A case of irreconcilable differences? Diabetes Care 1995;18:412-5.

13. Wagner EH, Bennett SM, Austin BT, et al. Finding common ground: patient-centeredness and evidence-based chronic illness care. $J$ Altern Complement Med 2005;11:S7-15.

14. Wagner EH. Chronic disease management: what will it take to improve care for chronic illness? Eff Clin Pract 1996;1:2-4.

15. Bensing J. Bridging the gap. The separate worlds of evidence-based medicine and patient-centered medicine. Patient Educ Couns 2000;39:17-25.

16. Rosemann T, Laux G, Szecsenyi J, et al. The chronic care model: congruency and predictors among primary care patients with osteoarthritis. Qual Saf Health Care 2008;17:442-6.

17. Gittell JH. Relationships between service providers and their impact on customers. J Serv Res 2002;4:299-311.

18. Gittell JH. Relational coordination: coordinating work through relationships of shared goals, shared knowledge, and mutual respect. In: Kyriakidou O, Özbilgin M, eds. Relational perspectives in organizational studies: a research companion. Cheltenham (UK): Edward Elgar Publishers, 2006:74-94.

19. Gittell JH. Supervisory span, relational coordination and flight departure performance: a reassessment of post-bureaucracy theory. Org Sci 2001;12:467-82

20. Hartgerink JM, Cramm JM, Bakker TJ, et al. The importance of multidisciplinary teamwork and team climate for relational coordination among teams delivering care to older patients. $J \mathrm{Adv}$ Nurs 2013;70:791-9.

21. Hartgerink J, Cramm JM, de Vos AJBM, et al. Situational awareness, relational coordination and integrated care delivery to hospitalized elderly in the Netherlands: a comparison between hospitals. BMC Geriatr 2014;14:3.

22. Cramm JM, Hoeijmakers M, Nieboer AP. Relational coordination between community health nurses and other professionals in delivering care to community-dwelling frail people. J Nurs Manage 2013;22:170-6.

23. Weinberg DB, Lusenhop W, Gittell JH, et al. Coordination tetween formal providers and informal caregivers. Health Care Manage $R e$ 2007;32:140-50.

24. Warfield ME, Chiri G, Leutz WN, et al. Family well-being in a participant-directed Autism Waiver program: the role of relational coordination. J Intel Dis Res 2013. doi:10.1111/jir.12102

25. Cramm JM, Nieboer AP. Short and long term improvements in quality of chronic care delivery predict program sustainability. Soc Sci Med 2014;101:148-54.

26. Tsai AC, Morton SC, Mangione CM, et al. A meta-analysis of interventions to improve care for chronic illnesses. Am J Manag Care 2005;11:478-88.

27. Cramm JM, Adams SA, Walters $\mathrm{BH}$, et al. The role of disease management programs in the health behavior of chronically ill patients. Patient Educ Couns 2014;87:411-5.

28. Adams SG, Smith PK, Allan PF, et al. Systematic review of the chronic care model in chronic obstructive pulmonary disease prevention and management. Arch Intern Med 2007;167:551-61.

29. Lemmens KMM, Rutten-Van Mölken MPMH, Cramm JM, et al. Evaluation of a large scale implementation of disease management programmes in various Dutch regions: a study protocol. BMC Health Serv Res 2011;11:6.

30. Cramm JM, Nieboer AP. High-quality chronic care delivery improves experiences of chronically ill patients receiving care. Int J Qual Health Care 2013;25:689-95.

31. Gittell JH, Douglass A. Relational bureaucracy: structuring reciprocal relationships into roles. Acad Manage Rev 2012;37:709-33.

32. Glasgow RE, Whitesides $\mathrm{H}$, Nelson CC, et al. Use of the Patient Assessment of Chronic IIIness Care (PACIC) with diabetic patients: relationship to patient characteristics, receipt of care, and self-management. Diabetes Care 2005;28:2655-61.

33. Cramm JM, Nieboer AP. Factorial validation of the Patient Assessment of Chronic Illness Care (PACIC) and PACIC short version (PACIC-S) among cardiovascular disease patients in the Netherlands. Health Qual Life Outcomes 2012;10:104.

34. Gugiu C, Coryn CLS, Applegate B. Structure and measurement properties of the Patient Assessment of Chronic Illness Care instrument. J Eval Clin Pract 2010;16:509-16.

35. Rosemann T, Laux G, Droesemeyer S, et al. Evaluation of a culturally adapted German version of the patient assessment of 
chronic illness care (PACIC 5A) questionnaire in a sample of osteoarthritis patients. J Eval Clin Pract 2007;13:806-13.

36. Schmittdiel J, Mosen DM, Glasgow RE, et al. Patient assessment of chronic illness care (PACIC) and improved patient-centered outcomes for chronic conditions. J Gen Int Med. 2007;23:77-80.

37. Wensing M, van Lieshout J, Jung HP, et al. The Patients Assessment Chronic Illness Care (PACIC) questionnaire in the Netherlands: a validation study in rural general practice. BMC Health Serv Res 2008;8:182.

38. Bodenheimer T, Lorig K, Holman $\mathrm{H}$, et al. Patient self-management of chronic disease in primary care. JAMA 2002;288:2469-75.
39. Institute of Medicine. Unequal treatment: confronting racial and ethnic disparities in health care. In: Smedley BD, Stith AY,

Nelson AR, eds. Washington, DC: National Academies Press, 2003. http://www.iom.edu/Reports/2002/Unequal-Treatment-ConfrontingRacial-and-Ethnic-Disparities-in-Health-Care.aspx\#sthash. PZGdD8ZA.dpuf

40. Seeleman C, Suurmond J, Stronks K. Cultural competence: a conceptual framework for teaching and learning. Med Educ 2009;43:229-37.

41. Mackenzie TA, Greenaway-Coates A, Djurfeldt MS, et al. Use of severity of illness to evaluate quality of care. Int J Qual Health Care 1996;8:125-30. 